\title{
Saint-Bertrand-de-Comminges « Lugdunum Convenarum »
}

Présentation

Michel Vidal

\section{(2) OpenEdition \\ Journals}

Édition électronique

URL : http://journals.openedition.org/adlfi/10528

ISSN : 2114-0502

Éditeur

Ministère de la culture

Référence électronique

Michel Vidal, «Saint-Bertrand-de-Comminges «Lugdunum Convenarum » », ADLFI. Archéologie de la France - Informations [En ligne], Midi-Pyrénées, mis en ligne le 01 mars 1997, consulté le 23 avril 2019. URL : http://journals.openedition.org/adlfi/10528

Ce document a été généré automatiquement le 23 avril 2019

(c) Ministère de la Culture et de la Communication, CNRS 


\title{
Saint-Bertrand-de-Comminges «Lugdunum Convenarum »
}

\author{
Présentation
}

Michel Vidal

Date de l'opération : 1990 - 1992 (PC)

1 La reprise des fouilles en 1985 (Gallia, 1986 : 316) sur ce site d'intérêt national (compris dans la loi de programme 1988-1992 du ministère de la Culture relative au Patrimoine monumental), résulte de l'implication directe du service régional de l'Archéologie dans une opération de grande envergure.

2 En effet, la restauration du site et sa mise en valeur ne pouvaient se faire qu'à l'issue de fouilles extensives devant permettre de rétablir les bases d'une topochronologie générale et d'une évolution architecturale propre à l'avancement de la recherche. Ainsi, après une année d'évaluation en 1985, deux programmes trisannuels (1986-1988; 1989; 1990-1992) ont permis de réaliser les objectifs scientifiques prioritaires sur le centre civique de la ville antique [ (Fig. $n^{\circ} 1:$ Plan général), plan général].

3 Les résultats de ces recherches qui renouvellent une bonne part des connaissances acquises anciennement sur le site ont fait l'objet de plusieurs articles et d'une synthèse parus dans Aquitania, Journal of Roman Archaeology, Guide Archéologique de la France.

4 Une connaissance accrue des problèmes liés à la restitution et à une meilleure compréhension des critères architecturaux issus de chaque fouille, résultent également des travaux de l'Institut de recherche sur l'Architecture antique (IRAA/CNRS), notamment les contributions de Jean-Louis Paillet (bureau d'Aix-en-Provence) et de M. Fincker, J.-M. Labarthe, R. Monturet (bureau de Pau). Ces recherches sont maintenant prolongées par une étude de restitution volumétrique du centre monumental placée sous la responsabilité de M. Fincker.

5 Les équipes de fouilles qui se sont succédé depuis 1985 et jusqu'en 1992 sont pluridisciplinaires et interinstitutionnelles. Elles résultent d'initiatives de la direction des 
Antiquités historiques (R. Lequément) puis à partir de 1989 par M.-G. Colin. C'est sous son autorité que cette recherche, coordonnée jusqu'alors par la direction des Antiquités, a été menée au sein d'un projet collectif de recherche (Lugdunum de Convènes), d'abord sous la responsabilité de Jean Guyon (1989-1992), directeur de recherche au CNRS, puis de JeanMarie Pailler (1993), professeur à l'université de Toulouse - Le-Mirail.

Sous leurs efforts conjugués, les fouilles se sont étendues, et c'est le lieu ici de remercier :

7 À cette liste, correspondant aux responsables d'opération, on ajoutera celles et ceux qui ont largement participer aux prospections (cf. infra) :

Les résultats déjà acquis mettent en évidence l'importance des données produites par ces équipes de recherche, soutenues sur le plan technique et de l'organisation scientifique des chantiers par B. Marty (ingénieur au service régional de l'Archéologie).

Assurer la continuité des recherches sur ce site exceptionnel de notre histoire demeure l'objectif prioritaire du service régional de l'Archéologie.

\section{ANNEXES}

Fig. $n^{\circ} 1$ : Plan général

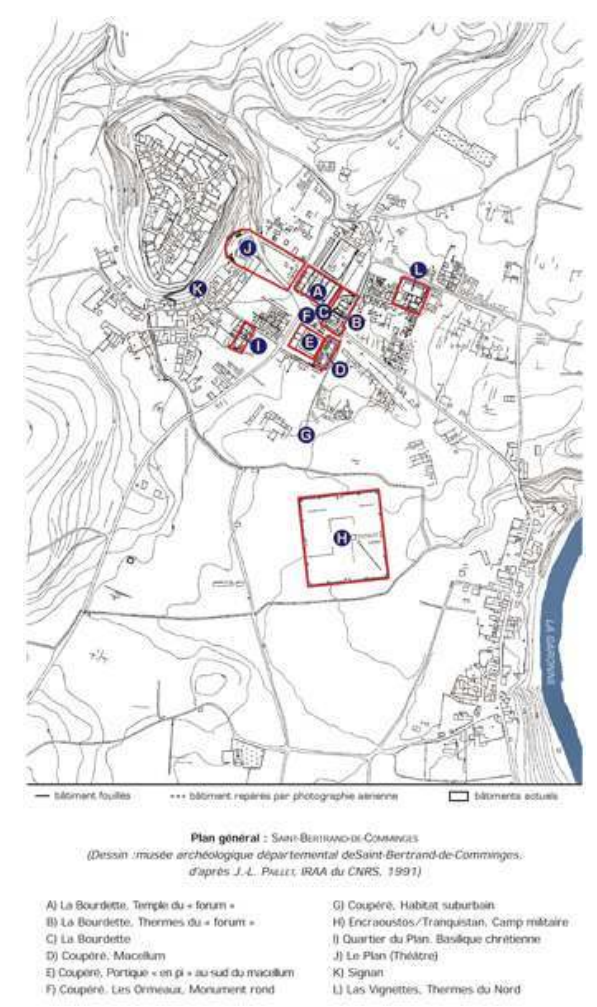

Auteur(s) : Paillet, Jean-Louis. Crédits : Gi 1997 ; CNRS Éditions 1998 (1991) 
INDEX

Index chronologique : Antiquité romaine

Index géographique : Midi-Pyrénées, Haute-Garonne, Saint-Bertrand-de-Comminges

operation projet collectif de recherche (PC) 